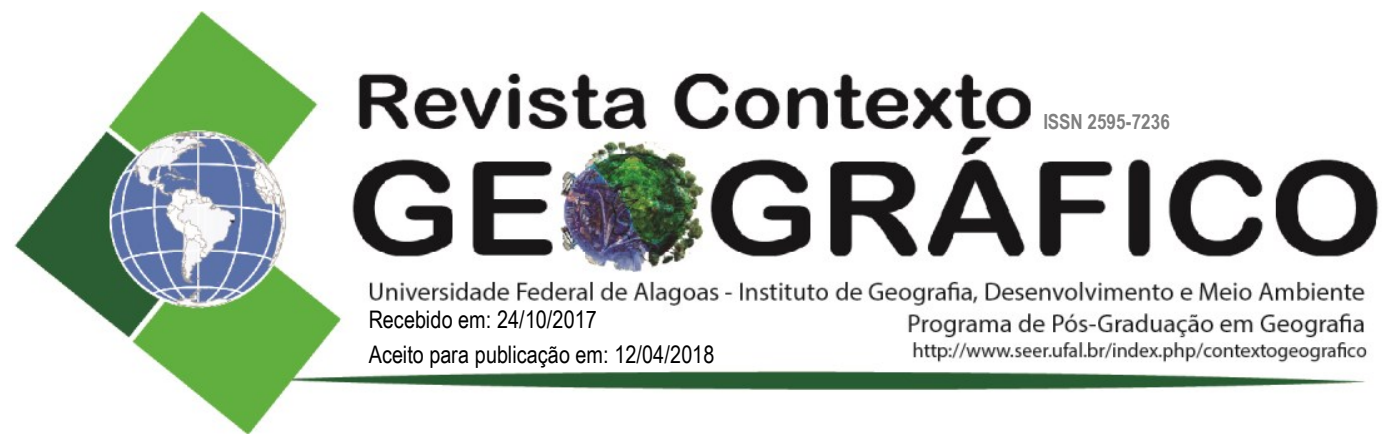

\title{
TERRITÓRIO, NORMAS E FINANÇAS: REFLEXÕES ACERCA DA LEGISLAÇÃO REFERENTE AO JOGO DO BICHO NO BRASIL
}

\author{
Leonardo Sena do Carmo \\ Mestrando do Programa de Pós-Graduação em Geografia Humana da Universidade de São \\ Paulo, Faculdade de Filosofia, Letras e Ciências Humanas, São Paulo, SP, Brasil \\ leonardo.sena@usp.br \\ Dhiego Antonio de Medeiros \\ Professor da Universidade Estadual de Alagoas, Campus V, União dos Palmares, AL, Brasil \\ dhiego.medeiros@uneal.edu.br
}

\begin{abstract}
RESUMO - Surgido no final do século XIX no Parque Jardim Zoológico no Rio de Janeiro, o Jogo do Bicho ficou marcado como uma atividade de alta rentabilidade financeira e por não atender as exigências estabelecidas pela lei. Nesse sentido, o objetivo do trabalho é compreender como a norma se tornou um elemento fundamental no que concerne a organização do Jogo do Bicho. Visando uma análise geográfica sobre o objeto proposto, faz-se necessário chamar atenção às contribuições de Santos (1996; [1996] 2014) e Antas Jr. (2005) sobre conteúdos normativos e território usado. Já, com relação aos trabalhos que se referem ao Jogo do Bicho, verificou-se as proposituras de Costa ([1938] 2003), Soares (1993), Santos (1995), DaMatta e Soárez (1999), Torcato (2011) e Chazkel (2014). Destarte, com a realização da pesquisa, foi possível trazer à luz o conjunto de normas referentes à política de regulamentação do Jogo do Bicho visando a sua extinção no país, haja vista a significativa redução da renda das loterias da União pela concorrência com a atividade em destaque. Nesse contexto, a norma assume um papel central, sendo carregada de um pluralismo jurídico no desenvolvimento do Jogo do Bicho.
\end{abstract}

Palavras-chave: Atividade Ilegal; Rentabilidade financeira; Conteúdos normativos; Território usado.

\section{TERRITORY, NORMS AND FINANCE: REFLECTIONS ON THE LEGISLATION REFERENT TO THE JOGO DO BICHO IN BRAZIL}

\begin{abstract}
Arising at the end of the 19th century in the Parque Jardim Zoológico (Park Zoo) in Rio de Janeiro, the Jogo do Bicho was marked as an activity of high financial profitability and for not meeting the requirements established by law. In this sense, the objective of the work is to understand how the norm has become a fundamental element in what concerns the organization of the Jogo do Bicho. Aiming at a geographic analysis of the proposed object, it is necessary to draw attention to the contributions of Santos (1996; [1996] 2014) and Antas Jr. (2005) about normatives contents and territory used. Already, in relation to the works that refer to the Jogo do Bicho, was verified the propositions of Costa ([1938] 2003), Soares (1993), Santos (1995), DaMatta and Soárez (1999), Torcato (2011) and Chazkel (2014). So, with the accomplishment of the research, it was possible to evidence the set of norms referent the regulation policy of the Jogo do Bicho, aiming at its extinction in the country, due to the significant reduction of the income of the Union lotteries by competition with the activity in featured. In this context, the norm assumes a central role, being loaded with a legal pluralism in the development of the Jogo do Bicho.
\end{abstract}

Keywords: Illegal Activity; Financial profitability; Normative content; Territory used. 


\section{INTRODUÇÃO}

O mundo contemporâneo é marcado fortemente por uma verdadeira "expansão das finanças" (CONTEL, 2006) em suas diferentes modalidades, desde formas que estão amparadas pela norma, como também aquelas que possuem sua atuação restrita pela ação coercitiva da norma. Por exemplo, o Jogo do Bicho, que é uma contravenção penal desde 1941 por ser considerado um jogo de azar, mas que se sobressai às imposições da norma, utilizando-se dos mais derivados artifícios para perdurar até os dias atuais como uma das principais atividades lotéricas do país.

O Jogo do Bicho tornou-se um elemento bastante significativo da cultura popular brasileira ao longo do século passado, haja vista todo o simbolismo que circunda a loteria e sua afirmação na sociedade como uma atividade comum no cotidiano da maior parte das populações urbanas. Surgido em 03 de julho de 1892 no Parque Jardim Zoológico na cidade do Rio de Janeiro como uma estratégia de arrecadação de recursos para saldar os gastos do Parque Jardim Zoológico, que passava por sérias dificuldades financeiras.

O Barão de Drummond, proprietário do estabelecimento em 1889 já solicitava uma subvenção em requerimento à Câmara Municipal, pois naquele ano o zoológico já passava por problemas financeiras. No entanto, o pedido realizado por Drummond não foi aceito integralmente, mas o mesmo foi ressarcido com uma verba de 10 contos de réis. Porém, com a proclamação da República no mesmo ano, esse auxílio logo foi visto como privilégio baseado na amizade entre o imperador D. Pedro II, (deposto meses antes), e o Barão de Drummond, consequentemente a subvenção foi indeferida (MAGALHÃES, 2005).

O Jogo do Bicho representava uma opção de entretenimento para população na capital da República, e uma estratégia importante de arrecadação de recursos para o Barão. Segundo Costa ([1938] 2003, p. 543):

Cada visitante do Jardim, quando comprava a sua entrada, com ela recebia a indicação de um animal representando a possibilidade de um prêmio vinte vezes maior que a soma despendida. Custando esse ticket mil-réis, estava ele, portanto, habilitado a receber, caso lhe fosse a sorte favorável, vinte mil-réis. Era o jogo.

Assim sendo, é importante chamar atenção para os trabalhos de Chazkel (2014), "Leis da sorte: o jogo do bicho e a construção da vida pública urbana" e de Santos (1996), "O retorno do território", que possibilitam, por um lado, compreender a historicidade da referida atividade econômica e a problemática relacionada à "norma" e, por outro lado, apreender o papel do território e as variáveis vigentes no período. Esses trabalhos se revelaram importantes pela possibilidade de desvendar as incógnitas que circundam a prática do Jogo do Bicho. Logo, utilizando-se das ideias de Chazkel (2014), o processo de criminalização de atividades como o Jogo do Bicho é uma característica inerente à vida pública urbana e moderna.

As contribuições de Santos (1996; [1996] 2014) permitirão pensar o objeto de estudo à luz de uma teoria geográfica, uma vez que são identificadas na cidade diversas formas: capital, trabalho e organização. Logo, verificou-se que o papel que a norma assume para a análise do trabalho é de suma importância para compreensão do processo histórico e organizacional do Jogo do Bicho até os dias atuais. Nesse sentido, uma investigação sobre a natureza normativa da atividade permitirá entender como se deu o processo de espacialização da atividade em seus diferentes níveis de ação no uso do território.

Dessa forma, buscou-se no presente trabalho realizar uma revisão histórica sobre a legislação referente ao Jogo do Bicho no Brasil. Logo, a importância do estudo visa elucidar um tema que é ao 
mesmo tempo "antigo" e aparentemente não suficientemente explorado pelas Ciências Humanas e Sociais. Com a realização desta investigação, portanto, foi possível compreender como a norma assume um papel central na organização do Jogo do Bicho, ou seja, o poder coercitivo que a atividade sofreu a partir "repressões" advindas das normas, forçou a atividade criar diversos mecanismos operacionais para se capilarizar e solidificar-se no território.

\section{A NORMA E A POLÍTICA DE REGULAMENTAÇÃO DO JOGO DO BICHO NO PAÍS}

Sabe-se das contribuições seminais de Friedrich Ratzel para o pensamento geográfico, sobretudo no que diz respeito às concepções de Estado-nação e da ideia de território como uma noção político-administrativa caracterizada, assim, pelo entendimento de soberania no sistema jurídico, no qual todo indivíduo é obrigado a cumprir determinadas normas estabelecidas pelo Estado. Todavia, como lembrou Santos (1996) é preciso superar a noção de território herdada da Modernidade, pois: "O território são formas, mas o território usado são objetos e ações, sinônimo de espaço humano, espaço habitado." (SANTOS, 1996, p. 15). Desse modo, parte-se da premissa de que o espaço geográfico é constituído por uma interação entre objetos e ações, praticado e humanizado por diversos agentes, inclusive "agentes ilegais", a título de exemplo, os banqueiros do Jogo do Bicho.

Tendo isso em vista, para a realização de um estudo sobre uma atividade que não atende as exigências estabelecidas pela norma, como o Jogo do Bicho, o espaço geográfico deve ser entendido como espaço banal, assim constituído como o espaço de todos os homens, de todas as instituições, de todas as empresas (SANTOS, 1996), haja vista que esse constitui o caminho mais propício para uma análise geográfica. Portanto, concebendo que o Estado não é o único agente produtor de normas, torna-se visível que as instituições são por excelência produtoras de normas. Desse modo, como afirmou Milton Santos (1996), as instituições ganham formas geográficas, ou seja, elas se geografizam. Por isso, é importante distinguir o território como norma (infraestrutura, meio ecológico, firmas) e o território normado (leis, diretrizes, resoluções).

Como acentuou Antas Jr. (2005, p. 18): "Essa é uma das dimensões da realidade territorial que o conhecimento de alguns fundamentos do direito proporciona para o desenvolvimento da ciência geográfica [...]". A regulação, por exemplo, é um conceito oriundo do direito, mas que estabelece interface com a geografia. Basta observar a ação do Estado na tentativa de regulação do Jogo do Bicho a partir da criação de vários decretos, leis, etc. Assim, a norma surge como um importante instrumento utilizado na política de regulamentação do Jogo do Bicho no país.

Ainda que o Estado seja uma expressiva instância no processo de regulação social, pode-se constatar a existência de uma lacuna entre aquilo que a lei determina (autoritária, coercitiva, codificada e universal) e o costume (orgânico, informal, particular), pois a primeira é definida pela legislação do Estado e a última, é de cunho popular (CHAZKEL, 2014). Assim, não é demais destacar que a "via" do costume é um traço fundamental e indissociável dos processos históricos de formação dos países subdesenvolvidos, historicamente espoliados e dependentes economicamente, apresentam diferentes níveis de renda, capital e trabalho, revelando, portanto, capacidades diferentes de consumo, o que culminou com a conformação de dois subsistemas urbanos: o superior e o inferior, que de acordo com Santos ([1975] 2008) explicam a organização do espaço dos países subdesenvolvidos.

Ora, as sucessivas modernizações "seletivas" e incompletas que caracterizam a história dos países subdesenvolvidos, cristalizaram, pois, formas geográficas concretas e mais acirradas, de racionalidades também historicamente responsáveis pela organização e regulação dos seus territórios. Nesse sentido, faz-se necessário acentuar que o Jogo do Bicho não foge à regra. 
Surgido como atividade que nasce para arrecadar fundos para a difícil situação econômica que o Parque Jardim Zoológico vivenciava, a atividade apresentou-se para o Estado como uma prática que logo precisaria desaparecer. Para isso, fazia-se necessária uma política normativa eficiente. Assim, através da pesquisa acerca da legislação referente ao Jogo do Bicho no Brasil, observouse que o Estado desenvolveu uma série de normas na tentativa de regular essa atividade.

Para isso, o primeiro passo foi o Decreto $\mathrm{n}^{\circ} 133$, de 10 de abril de 1895 , em que a loteria é proibida oficialmente, ou seja, o Barão de Drummond, dono do estabelecimento, tinha o monopólio de comercializar "jogos públicos e lícitos" no Parque Jardim Zoológico, no entanto, quando o Jogo do Bicho começava a figurar como jogo de azar para as autoridades, o Barão perde o monopólio da atividade dentro do Zoológico. Um elemento importante a ser destacado centraliza-se no fato de não existir uma norma específica para a atividade, levando em consideração que o Jogo do Bicho surge apenas dois anos após a promulgação do Código Penal de 1890. Em seguida, os repressores utilizaram-se do Decreto $\mathrm{n}^{\circ}$ 847, de 11 de outubro de 1890, art. $367^{\circ}$ das contravenções penais, que tratava de loterias ou rifas não permitidas pelo Estado. Mesmo assim, por se mostrar uma atividade muito rentável, alguns agentes perceberam a sua lucratividade e começaram a financiar vários "jogos do bicho".

Através do Decreto $\mathrm{n}^{\circ} 41$, de 17 de maio de 1893, o Estado, visando a figura dos bookmakers, caçava as licenças que alguns agentes tinham para comercializar loterias pela cidade, além de proibir lojas de venderem jogos considerados de azar, loterias estrangeiras ou de outros estados que não os permitidos. Sem dúvida, entre os jogos de azar proibidos já figurava o Jogo do Bicho.

Para Damatta e Soáres (1999, p. 75), "Vale anotar que o "fazedor" ou "editor de livros", o bookmaker, é rigorosamente um mediador, tal como o recebedor de apostas que, com seu registro de palpites escritos, fazia os livros-caixa dos banqueiros de jogo." Ainda sobre a importância desses agentes para a difusão e permanência do Jogo do Bicho, ressaltam os referidos autores:

\begin{abstract}
A inovação promovida pelos bookmakers facilitou as apostas, permitindo que as pessoas jogassem sem deixar seus bairros e residências, o que virtualmente liquidava o monopólio espacial do barão, pois agora já não era necessário ir ao Zoológico. Tal possibilidade inventa também outro traço típico do jogo do bicho, qual seja: a possibilidade de a classe média jogar a domicílio, confortavelmente, sem sair de casa ou arriscar-se. Já não era preciso vestir-se ou esperar pela noite, como ocorria quando se queria ir a um cassino ou ao Jóquei Clube. Quem podia, tinha um "moleque" ou "criado" que, entre outras coisas, apanhava as compras no armazém e fazia o jogo do bicho dos seus patrões. (DAMATTA; SOÁRES, 1999, p. 75)
\end{abstract}

Mesmo com essas normas estabelecidas para regulamentar o Jogo do Bicho, a loteria persistia cada vez mais solidificada no território. Logo, era preciso estabelecer uma norma que promovesse uma grande repressão a atividade. Assim sendo, criou-se a Lei $\mathrm{n}^{\circ} 628$, de 28 de outubro de 1899, conhecida como "Lei Alfredo Pinto", válida em todo território nacional. A referida norma promovia algumas mudanças no Código Penal de 1890. Essa norma trazia o espírito moralizante e o discurso de uma sociedade capitalista em que era preciso valorizar o trabalho e a família. Torcato (2011, p. 124) lembrou que com essa lei "Novas concessões foram feitas à polícia, através da Lei Alfredo Pinto, o que permitiu que algumas autoridades policiais agissem como verdadeiros justiceiros [...]".

Nessa perspectiva, é importante dizer que mesmo o Jogo do Bicho sofrendo duras repressões, uma característica central em sua história no que concerne a norma é que até o Decreto $\mathrm{n}^{\circ} 2.321$, 
de 20 de dezembro de 1910, o Jogo do Bicho não aparecia citado em nenhuma lei, ou seja, existia uma grande ambiguidade e confusão para se julgar casos relacionadas ao Jogo do Bicho. Destarte, o Decreto ${ }^{\circ} 231$, de 20 de dezembro de 1910 altera o art. $367^{\circ}$ do Código Penal de 1890 e a Lei n ${ }^{\circ} 628$, surgindo uma discreta menção a atividade: "Entre os processos de sorteio a que se refere o $\mathrm{n}$. I do paragrapho antecedente estão comprehendidos os symbolos, as figuras e as vistas cinematographicas" e as penas foram reajustadas de 2 para 6 meses de prisão.

A primeira norma a destinar um artigo específico ao Jogo do Bicho vem surgir apenas em 1932, pelo Decreto $\mathrm{n}^{\circ} 21.143$, de 10 de março, em seu artigo $15^{\circ}$, que estipula, "É inafiançável a contravenção, denominada "jogo do bicho", praticada mediante a venda de cautelas, bilhetes, papéis avulsos, com ou sem dizeres, ou ainda sob quaisquer outras modalidades." O que se pode perceber é que existe uma distância temporal muito grande até que se estabeleça uma norma específica para a atividade. Nesse sentido, uma característica inerente à atividade durante sua história de espacialização no país é a ambiguidade referente a norma. Chazkel (2014) nos lembrou que durante os primeiros 35 anos da atividade, apenas $4 \%$ dos casos no Rio de Janeiro tinham terminado em condenação, isso permite dizer que a falta de critérios normativos permitiu que a atividade se organizasse, se espalhasse e se solidificasse no território, mesmo sendo uma atividade que foge a norma.

À guisa de exemplo, a autora elucida que no Distrito Federal do Rio de Janeiro, entre 1906 a 1917, os casos relacionados ao Jogo do Bicho tinham uma absolvição de aproximadamente $87 \%$, enquanto os casos de vadiagem tinham uma absolvição de aproximadamente $69 \%$, ou seja, isso permitia aos agentes do Jogo do Bicho uma atuação mais intensa na prática da atividade sem receio de serem punidos.

A Lei $\mathrm{n}^{\circ} 3.688$, de 3 de outubro de 1941 é um marco histórico na atividade do Jogo do Bicho, pela primeira vez a loteria aparece na Lei das Contravenções Penais, especificamente no art. $58^{\circ}$ :

Explorar ou realizar a loteria denominada jogo do bicho, ou praticar qualquer ato relativo à sua realização ou exploração: Pena prisão simples, de quatro meses a um ano, e multa, de dois a vinte contos de réis. Parágrafo único. Incorre na pena de multa, de duzentos mil réis a dois contos de réis, aquele que participa da loteria, visando a obtenção de prêmio, para si ou para terceiro.

O Decreto-Lei $\mathrm{n}^{\circ} 6.259$, de 10 de fevereiro de 1944, especificamente em seu artigo $59^{\circ}$, tornou o Jogo do Bicho uma atividade inafiançável e agora considerava as listas com indicações claras ou disfarçadas como prova do ato contravencional. Antes desse decreto, mesmo sendo apreendidas, as listas do Jogo do Bicho não eram consideradas provas materiais suficientes.

É preciso dizer que o maior golpe contra os jogos de azar no Brasil ocorreu no governo do General Eurico Gaspar Dutra. O Decreto n ${ }^{\circ}$ 9.215, de 30 de abril de 1946, completando a vigência do art. $50^{\circ}$ da Lei de Contravenções Penais, proíbe a prática de jogos de azar em todo território nacional, ficando nulas todas as concessões, licenças ou autorizações dadas as autoridades federais, estaduais ou municipais. Para o aludido presidente, o país deveria seguir uma legislação penal dos povos cultos, baseada na tradição moral, jurídica e religiosa do povo brasileiro.

Um elemento muito importante que merece destaque é o poder financeiro que as loterias assumiram no país. Como lembrou Chazkel (2014, p. 72), "As loterias eram mais do que apenas um vício ou até mesmo um jogo; elas eram grandes negócios." Posto isso, verifica-se que o mercado lotérico, para alguns agentes, sempre representou um grande investimento em decorrência do retorno financeiro que essa atividade gera. Nesse sentido, as loterias sendo normatizadas ou não, sempre estiveram presentes no território por seu poderio financeiro, em 
vista disso, a norma que proibia a execução dos serviços lotéricos no país não demoraria muito tempo para ser suplantada.

O Decreto $\mathrm{n}^{\mathrm{o}} 50.954$, de 14 de julho de 1961 , no uso da atribuição do art. $87^{\circ}$, item I, concedeu o serviço da Loteria Federal a CEF. Já o Decreto-Lei no 204, de 27 de fevereiro de 1967, proibiu os estados de criarem novas modalidades de loterias, mantendo apenas aquelas criadas e ratificadas pela União em data anterior à sua vigência. Como observado, o art. $1^{\circ}$ determina que "A exploração de loteria, como derrogação excepcional das normas do Direito Penal, constitui serviço público exclusivo da União não suscetível de concessão e só será permitida nos termos do presente Decreto-lei."

Segundo Santos (1995), uma norma que possibilitou uma maior participação de agentes no Jogo do Bicho foi a Lei $\mathrm{n}^{\circ}$ 6.416, de 24 de maio de 1977, que deu uma nova redação ao inciso II do art. $323^{\circ}$ do Código de Processo Penal, em que tornou o Jogo do Bicho uma atividade afiançável. $O$ autor ressaltou que a partir da inserção dessa lei, a atividade assumia um caráter cada vez mais ativo no território, posto que, qualquer pessoa interessada "poderia" abrir um ponto na cidade, desde que não houvesse outro ponto no local. Dessa maneira, Santos (1995) afirmou que a consequência da adoção dessa lei foi um aumento considerável no número de banqueiros no Jogo do Bicho.

Na mesma perspectiva, Oliveira (2012) acentuou que a Lei $\mathrm{n}^{\mathrm{o}} 12.683$, de 09 de julho de 2012, alterou a Lei $\mathrm{n}^{\circ}$ 9.613, de 03 de março de 1998, sancionada pela presidente da república Dilma Rousseff, aumentou a punição sobre a exploração do Jogo do Bicho e de máquinas caça níqueis. Tendo em vista que "A criação da referida lei se justifica pelo fato de terem surgido, sobretudo na última década, diversas Comissões Parlamentares de Inquérito (CPI) que investigam o jogo do bicho e seu envolvimento com esquemas de corrupção e lavagem de dinheiro" (OLIVEIRA, 2012, p. 24).

Dessa maneira, essas atividades agora podem ser consideradas crimes e passam a ter punições mais rígidas, se constatada lavagem de dinheiro. Assim sendo, até a vigência da lei, poucas eram as atividades listadas que se enquadravam nessa categoria, além da possibilidade de recuperação de bens e valores ilícitos.

Um importante fato sobre a legislação brasileira é o descumprimento até mesmo dentro da própria instância Estadual, ou seja, o Estado de Alagoas é característico por possuir desde sua gênese elementos ambíguos e particulares que o destacam em sua formação histórica. Ao nos referirmos à prática da atividade lotérica, não difere disso. Nesse sentido, o Jogo do Bicho em Alagoas assumiu um caráter específico que o destacou em cenário nacional.

Primeiramente com a Lei $\mathrm{n}^{\mathrm{o}}$ 625, de 15 de janeiro de 2001, Alagoas instituiu a Loteria Social do Estado de Alagoas - LOTEAL e dá outras providências, mas analisando o Decreto-Lei $\mathrm{n}^{\circ}$ 204, de 27 de fevereiro de 1967, estava determinada a proibição da criação de novas loterias no país e caberia somente a União a concessão desses serviços. Posteriormente com a Resolução $n^{\circ} 002$, de 28 de maio de 2001, a LOTEAL regulamentou a Zooloteria - denominação dada a loteria do Jogo do Bicho em Alagoas -, fazendo licitações e "legalizando" algumas organizações que estavam permitidas a explorar o serviço do Jogo do Bicho no estado (Quadro 1). Segundo Ferreira (2004), o periódico Gazeta de Alagoas obteve acesso à cópia do contrato que estabelecia que $93 \%$ do faturamento iria para os banqueiros, enquanto o estado ficava apenas $\operatorname{com} 7 \%$. 
Quadro 1. Alagoas: empresas vencedoras

permitidas a executar o Jogo do Bicho no estado (2002)

\begin{tabular}{|c|l|}
\hline \multicolumn{1}{|c|}{ Cidades } & \multicolumn{1}{c|}{ Empresas Vencedoras } \\
\hline Área I - Maceió & $\begin{array}{l}\text { Lote 1 - Plínio Batista Júnior - ME. } \\
\text { Lote 2 - Laudjane de Lima Oliveira - ME. } \\
\text { Lote 3 - João Batista - ME. } \\
\text { Lote 4 - F.G. comércio Representações e Serviços } \\
\text { LTDA. } \\
\text { Lote 5 - Fábio Augusto Gomes Batista - ME. }\end{array}$ \\
\hline Área II - Arapiraca & Lote único - Carlos Jorge Pimentel da Silva - ME. \\
\hline Área III - Palmeira dos Índios & Lote único - Petrúcio Carlos Soares Basílio - ME. \\
\hline Área IV - Penedo & Lote único - Nordeste Loterias LTDA. \\
\hline Área V - São Miguel dos Campos & Lote Único: Fábio Augusto Gomes Batista- ME. \\
\hline Área VI - União dos Palmares & Lote Único: Plínio Batista Júnior-ME. \\
\hline Área VII - Delmiro Gouveia & Lote Único: Cheque Forte Loterias LTDA. \\
\hline Área VIII - Matriz de Camaragibe & Lote Único: Super Diversões Jóia LTDA. \\
\hline Área IX - Atalaia & $\begin{array}{l}\text { Lote Único: Di Loto Comércio, Distribuição, } \\
\text { Representações e Serviços LTDA. }\end{array}$ \\
\hline Área X - Rio Largo & Lote Único: João Batista ME. \\
\hline \multicolumn{2}{|c|}{ Fonte: LOTEAL (2001). Elaboração: Carmo (2016). }
\end{tabular}

No entanto, o promotor Sérgio Jucá entrou com uma Ação Direta de Inconstitucionalidade (ADI) contra a prática do Jogo do Bicho no estado, uma vez que não caberia ao estado "legalizar" uma atividade que a União julgou como contravenção penal pelo art. $58^{\circ}$ da Lei ${ }^{\circ}$ 3.688 , de 3 de outubro de 1941, e ainda mais, não poderia sequer instituir uma loteria. O meio encontrado foi a promulgação da $\mathrm{ADI} \mathrm{n}^{\circ}$ 3. 189-9, de 13 de dezembro de 2006, que caçou todas as licenças e "tornou" o Jogo do Bicho uma atividade "novamente" ilegal em Alagoas.

Outro elemento que também contribui para essa prerrogativa é a criação de Projetos de Lei apresentados no Congresso Nacional. Basta investigar o número de projetos que, em sua maioria, propõem a legalização. Silva (2006) lembrou que entre 1951-2004, existiam mais de 60 Projetos de Lei. Posto isso, DaMatta e Soárez (1999) acentuaram que o marco regulatório sobre a atividade, isto é, sua marginalização jurídica, assumiu um papel central no que tange ao desenvolvimento, organização, aceitação e difusão do Jogo do Bicho na paisagem urbana brasileira como a atividade lotérica mais duradoura e popular, assim como ocorreu com as religiões afro-brasileiras.

Nessa perspectiva, uma importante nota sobre a jurisprudência da atividade foi destaca por Soares (1993, p. 129-130):

\footnotetext{
"A oficialização seria o jogo ser controlado pelo governo. A legalização seria ele deixar de ser contravenção penal e continuar existindo na legalidade, permanecendo, no entanto, controlado pelos bicheiros. A legalização é defendida pela maioria dos parlamentares, autoridades policiais, pela maior parte da população e, obviamente, pelos próprios bicheiros."
}

Atualmente verifica-se a existência de dois Projetos de Lei que propõem a legalização tanto do Jogo do Bicho quanto de outros jogos não permitidos por lei, tendo como principal argumento a 
alegação de que a legalização destes seriam mecanismos robustos para a retomada do crescimento econômico do país. Existe um projeto na Câmara dos Deputados composto pela comissão especial do Marco Regulatório dos Jogos no Brasil, Projeto de Lei (PL), n 442, de 21 de março de 1991, que avalia 14 propostas sobre a legalização do Jogo do Bicho, cassinos, bingos, caça-níqueis, tendo como relator o deputado Guilherme Mussi (PP/SP). Enquanto outro tramita no Senado, a partir do Projeto de Lei do Senado (PLS), $n^{\circ}$ 186, de 22 de abril de 2014, do senador Ciro Nogueira (PP-PI) e tem relatoria do senador Fernando Bezerra Coelho (PSBPE). Respaldado por estatísticas da World Lottery Association, Fernando Bezerra Coelho salientou que o mercado de loterias e jogos em 2014 movimentou cerca de US\$ 400 bilhões em todo o mundo, no entanto, oficialmente o Brasil só teve a participação de 1\% deste total, a partir das loterias administradas CEF.

Os jogos de azar, cada um com um modus operandi e a conjuntura que lhe deu origem, sempre representaram um segmento importante no que diz respeito a movimentação de capital e, portanto, na dinamização dos fluxos em escalas geográficas diversas. Ao tratar dos processos de globalização e das relações dos Estados nacionais com o sistema financeiro-corporativo, abertura dos mercados e a livre circulação dos capitais e de informação, Machado (2017, p. 326) assevera:

Além de atuar em setores tradicionais da economia, essas corporações estão presentes na ciência, na cultura, na tecnologia, nos sistemas de saúde, nos serviços sociais, no setor militar, nos transportes, na mídia, nos jogos de azar, no turismo e assim por diante.

Complementa a mesma autora:

Por sua vez, a imaterialidade dos fluxos financeiros e a materialidade dos Estados territoriais pressupõem a existência de sistemas legais que competem entre si, o que provoca uma crescente ambiguidade do binômio legal/ilegal nas sociedades atuais. (MACHADO, 2017, p. 327).

Assim, o projeto do senador Ciro Nogueira se baseia em grande parte num estudo coordenado pelo Instituto Jogo Legal (IJL), no qual foi constatado que o Jogo do Bicho é a loteria brasileira mais bem-sucedida financeiramente do país, mesmo sendo uma atividade que não possui respaldo perante as legislações vigentes. No estudo identifica-se que a atividade possuía cerca de 350 mil pontos de vendas distribuídos pelo país movimentando R $\$ 12$ bilhões anuais, enquanto que as loterias da CEF estavam sendo comercializadas através de 12.600 lotéricas, movimentando R \$ 11,4 bilhões.

O Jogo do Bicho produz uma lógica territorial própria, distribuído e orientado por ações imbuídas de intencionalidades, logo, os seus "pontos" representam o meio pelo qual as organizações fazem o uso do território. Como destacado, a expressiva capilaridade do Jogo do Bicho, confirma que a atividade possui sua forma geográfica diferente das demais loterias do país. Portanto, seja a partir de um ponto com infra-estrutura própria, de uma banca em via pública ou comercializado juntamente a outras atividades tradicionais de comércio e de serviços de caráter popular, a atividade revela sua forma operacional no uso do território.

Com base na revisão histórica realizada sobre a legislação inerente ao Jogo do Bicho, constatou-se a importância que ela, a norma, assume no processo organizacional da atividade. Nesse sentido, a norma surge como reguladora de determinadas relações sociais, no entanto, vale acentuar que as normas são indiscutivelmente carregadas de um pluralismo jurídico. Seguindo esse pensamento, o histórico de normas elaboradas para regulamentar o Jogo do Bicho comprova isso, ao passo que várias são as normas criadas com o intuito de impedir a prática da atividade. 


\section{CONSIDERAÇÕES FINAIS}

A partir da revisão histórica realizada sobre um dos elementos mais marcantes da cultura popular brasileira, como é o Jogo do Bicho, foi constatado que várias foram as tentativas de regulamentação da atividade no país. Sem sombra de dúvidas, um aspecto bastante relevante a ser considerado no Jogo do Bicho é sua natureza normativa, haja vista que a norma surge como elemento que tem por finalidade regular determinadas relações sociais. Contudo, é preciso lembrar que as normas são carregadas de pluralismo jurídico, podendo ser alteradas ou reformuladas de acordo com determinados comportamentos sociais.

O território como sinônimo de espaço habitado é o que vai autorizar instituições, como o Jogo do Bicho, a serem concebidas como produtoras de normas. Sendo assim, ao passo que o Estado elabora suas normas com o propósito de coibir a atividade, concomitantemente verifica-se a existência de normas criadas pelos banqueiros que permitem a difusão do Jogo do Bicho, acarretando uma relação de poder entre o Estado e as organizações da atividade. Isso irá ocasionar de um lado, a ação coercitiva da norma pelo Estado, do outro, a ação normativa do Jogo do Bicho alicerçada na flexibilidade e na força do costume popular para superar o poder coercitivo imposto pelo Estado.

Nesse sentido, as normas jurídicas regulam a produção dos sistemas técnicos e de ações sobre determinados objetos, conforme finalidades particulares socioeconômicas e de cada período histórico. Portanto, o interesse na regulação do Jogo do Bicho encontrou seu sentido em interesses particulares de grandes grupos sociais que concentravam o poder de comercializar as loterias. No entanto, como afirmou Antas Jr. (2005), o pluralismo jurídico advém também de poderes marginais, a exemplo do Jogo do Bicho, que também são criadores de normas e fortalecem suas ações no território.

Conforme destacou Chazkel (2014, p. 26): “A intervenção da lei no jogo do bicho, equivocada como muitas vezes foi, teve um impacto profundo no desenvolvimento histórico do jogo e na sociedade urbana." Indiscutivelmente, a norma teve um papel singular no desenvolvimento do Jogo do Bicho ao longo de sua existência, através dela, a atividade acentuou uma face "invisível" em sua lógica territorial, como também demandou um maior grau de organização para atuar e se difundir por todo território nacional.

\section{AGRADECIMENTOS}

Ao Conselho Nacional de Desenvolvimento Científico e Tecnológico (CNPq), pelo fomento ao projeto de pesquisa no período compreendido entre 2014 e 2015 (Edital 001/2014 $\mathrm{PIBIC/CNPq/UNEAL).}$

À Fundação de Amparo à Pesquisa do Estado de São Paulo (FAPESP), pelo fomento à pesquisa em desenvolvimento (Processo n ${ }^{\circ}$ 2017/22054-6).

\section{REFERÊNCIAS}

ALAGOAS. SUPREMO TRIBUNAL FEDERAL. ADI nº. 3. 189-9/AL. Relator: Min. Celso de Mello. Brasília, DF, 13/12/2006. Disponível em: $<$ http://redir.stf.jus.br/paginadorpub/paginador.jsp?docTP=AC\&docID=488656>. Acessado em: 08 de set. 2015.

ALAGOAS (Estado). Decreto ${ }^{\circ} 2.751$, de 26 de agosto de 2005. Altera a redação dos artigos 26 e 27 do decreto $\mathrm{n}^{\circ} 387$, de 29 de outubro de 2001, com as alterações introduzidas pelos decretos $\mathrm{n}^{\circ} \mathrm{S} 1.253$, de 26 de maio de 2003, e 2.408, de 16 de fevereiro de 2005. Gabinete Civil. Maceió, AL, 26 ago. 2005. 
Disponível em: $\quad<$ http://www.gabinetecivil.al.gov.br/legislacao/decretos/2005/08/decreto2751/?searchterm=decreto $>$. Acessado em: 08 set. 2015.

Decreto $\mathrm{n}^{\mathrm{o}} 3.043$, de $1^{\circ}$ de fevereiro de 2006. Altera a redação do art. 26 do decreto $\mathrm{n}^{\circ} 387$, de 29 de outubro de 2001, modificado pelos decretos $\mathrm{n}^{\mathrm{o}}$ 's 1.253, de 26 de maio de 2003, 2.408 de 16 de fevereiro de 2005 e 2.751 de 26 de agosto de 2005. Gabinete Civil. Maceió, AL, 1 fev. 2015. Disponível em: <http://www.gabinetecivil.al.gov.br/legislacaogabinete>. Acessado em: 08 set. 2015.

Decreto $\mathrm{n}^{\circ} 2.408$, de 16 de fevereiro de 2005. Altera a redação dos artigos 26 e 27 do decreto $\mathrm{n}^{\mathrm{o}} 387$, de 29 de outubro de 2001, com as alterações do decreto $\mathrm{n}^{\mathrm{o}} 1.253$, de 26 de maio de 2003. Maceió, AL, 16 fev. 2005. Gabinete Civil. Disponível em: $<$ http://www.gabinetecivil.al.gov.br/legislacao/decretos/2005/02/decreto-2408>. Acessado em: 08 set. 2015 .

Decreto $n^{\circ} 1.253$, de 26 de maio de 2003. Altera a redação dos artigos 26 e 27 do decreto $\mathrm{n}^{\circ} 387$, de 29 de outubro de 2001, que regulamentou a lei $\mathrm{n}^{0}$ 6.225, de 15 de janeiro de 2001, instituidora da loteria social do estado de alagoas - Loteal. Gabinete Civil. Maceió, AL, 26 mai. 2003. Disponível em: $<$ http://www.gabinetecivil.al.gov.br/legislacaogabinete>. Acessado em: 08 set. 2015.

Decreto $n^{\circ} 429$, de 14 de novembro de 2001. Regulamenta o parágrafro único do artigo $2^{\circ}$ da lei estadual $n^{\circ}$ 6.225, de 15 de janeiro de 2001 e dá outras providências. Maceió, AL, 14 nov. 2001. Gabinete Civil. Disponível em: <http://www.gabinetecivil.al.gov.br/legislacao/decretos/2001/11/decreto429\%20/pdf_view>. Acessado em: 08 set. 2015.

Decreto $\mathrm{n}^{\mathrm{o}} 387$, de 29 de outubro de 2001. Regulamenta as leis $\mathrm{n}^{\mathrm{o}} 6.225$, de 15 de janeiro de 2001 e $\mathrm{n}^{\circ}$ 6.263, de 18 de setembro de 2001, e dá outras providências. Gabinete Civil. Maceió, AL, 29 out. 2001. Disponível em: <http:/www.gabinetecivil.al.gov.br/legislacao/decretos/2001/10/decreto387\%20>. Acessado em: 08 set. 2015.

Lei delegada $\mathrm{n}^{\circ} 13$, de 17 de março de 2003. Altera dispositivos da lei $\mathrm{n}^{\circ} 6.225$, de 15 de janeiro de 2001, e dá outras providências. Gabinete Civil. Maceió, AL, 17 mar. 2001. Disponível em: <http://www.gabinetecivil.al.gov.br/legislacaogabinete>. Acessado em: 08 set. 2015.

Lei $n^{\circ} 6.225$, de 15 de Janeiro de 2001. Institui a loteria social do estado de Alagoas Loteal e dá outras providências. Gabinete Civil. Maceió, AL, 15 jan. 2001. Disponível em: $<$ http://www.gabinetecivil.al.gov.br/legislacao/leis/leis-ordinarias/2001/lei-ordinaria-6225>. Acessado em: 08 set. 2015.

Lei $n^{\circ} 6.263$, de 18 de setembro de 2001. Altera o art. $1^{\circ}$ da lei 6.225 de 15 de janeiro de 2001, publicada no doe de 16.01.2001, e adota outras providências. Gabinete Civil. Maceió, Al, 18 set. 2003. Disponível em: <www.gabinetecivil.al.gov.br/legislacao/leis/leis ordinarias/2001/lei.../file>. Acessado em: 08 set. 2015.

SECRETARIA SOCIAL DO ESTADO DE ALAGOAS. Resolução nº 002, de 28 de maio de 2001. Dispõe sobre a modalidade de loteria de concurso ou prognóstico conforme "caput" do artigo $4^{\circ}$ da Lei Estadual n. ${ }^{\circ}$ 6.225, de 15 de janeiro de 2001, e dá outras providências. Diário Oficial de Alagoas, Maceió, AL, 30 mai. 2001. Seção 1, p. 8. Disponível em: <http://doeal.com.br/>. Acessado em 09 set. 2015.

ANTAS JR, Ricardo Mendes. Território e regulação: espaço geográfico, fonte material e não-formal do direito. São Paulo: Associação Editorial Humanitas: FAPESP, 2005. E-book. Disponível em: $<$ http://ricardoantasjr.org/wp-content/uploads/2012/03/livro.pdf>. Acesso em: 19 mai. 2016.

BRASIL. Decreto $n^{\circ} 21.143$, de 10 de março de 1932. Regula a extração de loterias. Portal da Câmara dos Deputados. Rio de Janeiro, RJ, 21 mar. 1932. Disponível em: $<$ http://www2.camara.leg.br/legin/fed/decret/1930-1939/decreto-21143-10-marco-1932-514738publicacaooriginal-1-pe.html>. Acesso em: 27 dez. 2015.

Decreto $\mathrm{n}^{\circ}$ 2.321, de 30 de dezembro de 1910. Orça a receita geral da Republica dos Estados

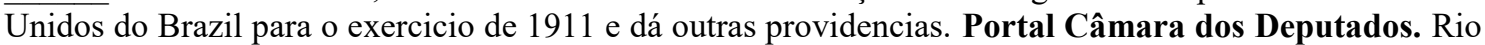
de Janeiro, RJ, 30 dez. 1910. Disponível em: <http://www2.camara.leg.br/legin/fed/decret/19101919/decreto-2321-30-dezembro-1910-586767-publicacaooriginal-110408-pl.html>. Acesso em: $27 \mathrm{dez}$. 2015. 
Decreto $\mathrm{n}^{\mathrm{o}} 2.980$, de 24 de janeiro de 1941. Consolida as disposições sobre o serviço de loterias e dá outras providências. Portal Câmara dos Deputados. Rio de Janeiro, RJ, 27 jan. 1941. Disponível em: $<$ http://www2.camara.leg.br/legin/fed/declei/19401949/decretolei298024janeiro1941412917publicacaoor iginallpe.html>. Acessado em: 09 mai. 2015.

Decreto $n^{0}$ 50.954, de 14 de julho de 1961. Dispõe sobre a execução do serviço da Loteria Federal e dá outras providências. Portal Câmara dos Deputados. Rio de Janeiro, RJ, 14 jul. 1961. Disponível

em:

$<$ http://www2.camara.leg.br/legin/fed/decret/19601969/decreto5095414julho1961390555publicacaoorigi nallpe.html>. Acessado em: 30 mai. 2015.

Decreto $\mathrm{n}^{\circ} 854$, de 12 de Novembro de 1938. Dispõe sobre o serviço de loterias e dá outras providências. Portal Câmara dos Deputados. Rio de Janeiro, RJ, 16 nov. 1938. Disponível em: $<$ http://www2.camara.leg.br/legin/fed/declei/19301939/decretolei85412novembro1938344875publicacao originallpe.html. Acessado em: 05 mai. 2015.

Decreto $n^{\circ} 9.215$, de 30 de abril de 1946. Próibe a prática ou a exploração de jogos de azar em todo o território nacional. Portal Câmara dos Deputados. Rio de Janeiro, RJ, 30 abr. 1946. Disponível em: $<$ http://www2.camara.leg.br/legin/fed/declei/19401949/decretolei921530abril1946417083publicacaoorigina 11pe.html>. Acessado em: 03 jul. 2015.

Decreto $\mathrm{n}^{\mathrm{o}}$ 847, de 11 de outubro de 1890. Promulga o Código Penal. Portal Câmara dos Deputados. Rio de Janeiro, RJ, 11 out. $1890 . \quad$ Disponível em: $<$ http://www2.camara.leg.br/legin/fed/decret/1824-1899/decreto-847-11-outubro-1890-503086publicacaooriginal-1-pe.html>. Acessado em: 09 mai. 2015.

Decreto-Lei $n^{\circ}$ 6.259, de 10 de fevereiro de 1944. Dispõe sobre o serviço de loterias e dá outras providências. Portal Câmara dos Deputados. Rio de Janeiro, RJ, 18 fev. 1944. Disponível em:

$<$ http://www2.camara.leg.br/legin/fed/declei/19401949/decretolei625910fevereiro1944416234publicacao originallpe.html. Acessado em: 30 mai. 2015

Decreto-Lei n ${ }^{\circ}$ 204, de 27 de fevereiro de 1967. Dispõe sôbre a exploração de loterias e dá outras providências. Portal Câmara dos Deputados. Brasília, DF, 25 fev. 1967. Disponível em: $<$ http://www2.camara.leg.br/legin/fed/declei/19601969/decretolei20427fevereiro1967373407publicac aooriginallpe.html>. Acessado em: 03 ago. 2015.

Lei ${ }^{\circ}$ 6.416, de 24 de maio de 1977. Altera dispositivos do Código Penal (Decreto-lei no 2.848, de 7 de dezembro de 1940), do Código de Processo Penal (Decreto-lei no 3.689, de 3 de outubro de 1941), da Lei das Contravenções Penais (Decreto-lei $\mathrm{n}^{\circ} 3.688$, de 3 de outubro de 1941), e dá outras providências. Portal Câmara dos Deputados. Brasília, DF, 07 jun. 1977. Disponível em: $<$ http://www2.camara.leg.br/legin/fed/lei/1970-1979/lei-6416-24-maio-1977-366407-retificacao-22245pl.html>. Acesso em: 03 ago. 2015.

Lei $\mathrm{n}^{\circ} 628$, de 28 de outubro de 1899. Amplia a ação penal por denúncia do Ministério Público, e dá outras providências. Portal Câmara dos Deputados. Rio de Janeiro, RJ, 28 out. 1899. Disponível em: $<$ http://www2.camara.leg.br/legin/fed/lei/18241899/lei62828outubro1899540691 publicacaooriginal4144 7pl.html>. Acessado em: 09 mai. 2015.

Lei $\mathrm{n}^{\circ}$ 3.688, de 3 de outubro de 1941. Leis das Contravenções Penais. Portal Câmara dos Deputados. Rio de Janeiro, RJ, 13 out. 1941. Disponível em: $<$ http://www2.camara.leg.br/legin/fed/declei/19401949/decretolei36883outubro1941413573publicacaoori ginallpe.html>. Acessado em: 03 ago. 2015.

Projeto de Lei $n^{\circ} 442$, de 21 de março de 1991. Dispõe sobre a legalização do jogo do bicho; altera o Decreto-lei $\mathrm{n}^{\mathrm{o}}$ 3.688, de 1941. Portal Câmara dos Deputados, Brasília, DF, 21 mar. 1999. Disponível em: $<$ http://www.camara.gov.br/proposicoesWeb/fichadetramitacao?idProposicao=15460>. Acesso em: 08 ago. 2017.

Projeto de Lei $n^{\circ} 186$, de 22 mar. 2014. Dispõe sobre a exploração de jogos de azar em todo o território nacional. Senado Federal, Brasília, DF, 22 mar. 2014. Disponível em: $<$ https://www25.senado.leg.br/web/atividade/materias/-/materia/117805>. Acesso em>08 ago. 2017.

CHAZKEL, Amy. Leis da sorte: o jogo do bicho e a construção da vida púbica urbana. Tradução de Vera Joscelyne. São Paulo: Editora da Unicamp, 2014. 
CONTEL, Fabio Betioli. Território e finanças: técnica, normas e novas topologias bancárias no Brasil. 2006. Tese (Doutorado em Geografia Humana) - Faculdade de Filosofia, Letras e Ciências Humanas, Universidade de São Paulo, São Paulo, 2006.

COSTA, Luís Edmundo de Melo Pereira da. Jogadores e jogatinas. In: O Rio de Janeiro do meu tempo. Brasília: Senado Federal, Conselho Editorial, [1938] 2003. cap. 28, p. 539-551. (Edições do Senado Federal, v. 1).

DAMATTA, Roberto; SOÁREZ, Elena. Águias, burros e borboletas: um estudo antropológico do jogo do bicho. Rio de Janeiro: Rocco, 1999.

FERREIRA, Arnaldo. Governo de Alagoas "legalizou" contravenção. Boletim de Notícias Lotéricas, 2004. Disponível em: <http://www.magocom.com.br/bnl/noticia.aspx?tipo=1\&cod=4092>. Acesso em: 04 jan. 2015.

MACHADO, Lia Osorio. O visível e o invisível: o sistema financeiro-corporativo mundial sob o prisma da extraterritorialidade e do binômio legal/ilegal. Geousp - Espaço e Tempo, v. 21, n. 2, p. 325-340, mai./ago. 2017. Disponível em: <http://www.revistas.usp.br/geousp/issue/view/6465>. Acesso em: 2017.

SANTOS, Jair Nascimento. Paratodos Bahia: uma organização no jogo do bicho, 1995. Dissertação (Mestrado em Administração) - Instituto de Ciências Sociais Aplicadas, Universidade Federal da Bahia, Salvador, 1995.

SANTOS, Milton. A natureza do espaço: técnica e tempo, razão e emoção. 4. ed., 8 reimpr. São Paulo: EDUSP, [1996] 2014. (Coleção Milton Santos, 1).

O espaço dividido: os dois circuitos da economia urbana dos países subdesenvolvidos. Tradução Myrna T. Rego Viana. 2. ed. 1 reimpr. São Paulo: EDUSP, [1975] 2008.

O Retorno do Território. In: SANTOS, Milton; SOUZA, Maria Adélia Aparecida de; SILVEIRA, María Laura (Org.). Território: globalização e fragmentação. 3. ed. São Paulo: HUCITEC; ANPUR, 1996. p. 15-20.

SOARES, Simone Simões Ferreira. O jogo do bicho: a saga de um fato social brasileiro. Rio de Janeiro: Bertrand Brasil, 1993.

TORCATO, Carlos Eduardo Martins. A repressão oficial ao jogo do bicho: Uma história dos jogos de azar em Porto Alegre (1885-1917). Dissertação (Mestrado em História) - Instituto de Filosofia e Ciências Humanas, Universidade Federal do Rio Grande do Sul, Porto Alegre, 2011.

Sítios Eletrônicos:

$<\mathrm{http}: / / w w w . i n s t i t u t o j o g o l e g a l . c o m . b r />$. INSTITUTO JOGO LEGAL (IJL). Acesso em: 13 jan. 2014. 